\title{
UMA ANÁLISE DA RELAÇÃO CAMPO-CIDADE NO MUNICÍPIO DE FEIRA DE SANTANA APÓS O PROCESSO DE INDUSTRIALIZAÇÃO DA BAHIA
}

\author{
AN ANALYSIS OF THE FIELD-CITY RELATIONSHIP IN THE COUNTY OF \\ "FEIRA DE SANTANA" AFTER THE INDUSTRIALIZATION PROCESS OF \\ BAHIA STATE
}

\begin{abstract}
ANÁLISIS DE LA RELACIÓN CAMPO-CIDADE EN EL MUNICIPIO DE "FEIRA DE SANTANA" DESPUÉS DEL PROCESO DE INDUSTRIALIZACIÓN DE BAHIA
\end{abstract}

Gesner Brehmer de Araújo Silva ${ }^{1}$

\section{Resumo}

A relação campo-cidade, entendida aqui como a exiguidade de delimitações ou limites entre os espaços urbanos e rurais e a similaridade de elementos entre ambos, sofreu e vem sofrendo transformações profundas no Brasil após o período da Segunda Guerra Mundial e, sobretudo, pelos processos de urbanização e industrialização ocorridos no século passado, delineando novos formatos de relações econômicas, produtivas, sociais e políticas. Sendo assim, o propósito deste artigo é analisar como o processo de industrialização e urbanização baiana no século passado alterou elou modificou a relação campo-cidade no município de Feira de Santana. Para isso, além de uma revisão teórica sobre o processo de industrialização baiana e a formação econômica do referido município, este trabalho se utilizou do banco de dados de instituições como o IBGE e o Censo de Agricultura Familiar. Como resultados, concluiuse que há uma transformação da estrutura local do rural para o urbano, com a sobreposição do último sobre o primeiro em diversas perspectivas, mas, em especial com mais ênfase na econômica.

Palavras-chave: Industrialização. Feira de Santana. Campo. Cidade. Urbanização.

\section{Abstract}

The country-city relationship, understood here as the smallness of boundaries or limits between urban and rural spaces and the similarity of elements between both, has undergone and has undergone profound transformations in Brazil after the Second World War and, above all, due to the processes urbanization and industrialization occurred in the last century, outlining new formats of economic, productive, social and political relations. Therefore, the purpose of this article is to analyze how the process of industrialization and urbanization in Bahia in the last century changed and / or modified the rural-city relationship in the municipality of Feira de Santana. For this purpose, in addition to a theoretical review of the Bahian

\footnotetext{
${ }^{1}$ Mestrando em Planejamento Territorial pela Universidade Estadual de Feira de Santana (UEFS). Graduado em Ciências Econômicas pela Universidade Estadual de Feira de Santana (UEFS). E-mail: gesnerbrehmer@hotmail.com

${ }^{2}$ Doutor em Educação e Contemporaneidade pela Universidade do Estado da Bahia e Mestre em Gestão Integrada de Organizações pela Universidade do Estado da Bahia (UNEB); especialista em Gestão Organizacional (lato sensu) e graduado em Ciências Econômicas pela Universidade Estadual de Feira de Santana (UEFS). Atua como docente no curso de Ciências Econômicas, Adiministração e Engenharia Agronômica da UEFS, na Pós-Graduação Lato sensu em Gestão Universitária e no Programa de Pós-Graduação em Planejamento Territorial (PLANTERR). Mestrado; Membro do Comitê de Iniciação Científica e Coordenador do Programa Incubadora de Iniciativas da Economia Popular e Solidária (IEPS), bem como líder do Grupo de Estudos e Pesquisas em Economia Popular e Solidária e Desenvolvimento Local Solidário(GEPOSDEL). E-mail: zeraimundo@uefs.br
} 
industrialization process and the economic formation of that municipality, this work used the database of institutions such as IBGE and the Census of Family Agriculture. As a result, it was concluded that there is a transformation of the local structure from the rural to the urban, with the latter overlapping the former in several perspectives, but, especially with more emphasis on the economic.

Keywords: Industrialization. Feira de Santana. Field. City. Urbanization.

\section{Resumen}

La relación país-ciudad, entendida aquí como la pequeñez de límites o límites entre espacios urbanos y rurales y la similitud de elementos entre ambos, ha sufrido y ha sufrido profundas transformaciones en Brasil después de la Segunda Guerra Mundial y, sobre todo, debido a los procesos. La urbanización y la industrialización ocurrieron en el siglo pasado, delineando nuevos formatos de relaciones económicas, productivas, sociales y políticas. Por lo tanto, el propósito de este artículo es analizar cómo el proceso de industrialización y urbanización en Bahía en el siglo pasado cambió y / o modificó la relación rural-ciudad en el municipio de Feira de Santana. Para este propósito, además de una revisión teórica del proceso de industrialización de Bahía y la formación económica de ese municipio, este trabajo utilizó la base de datos de instituciones como el IBGE y el Censo de Agricultura Familiar. Como resultado, se concluyó que hay una transformación de la estructura local de lo rural a lo urbano, y esta última se superpone a la primera en varias perspectivas, pero, especialmente con más énfasis en lo económico.

Palabras-Clave : Industrializacion. Feira de Santana. Campo. Ciudad. Urbanizacion

\section{INTRODUÇÃO}

Como argumentam Guerra e Teixeira (2002) e Cavalcantti (2008), a Bahia, no início dos anos 1960, coloca em prática uma política de desenvolvimento industrial através de um processo de intervenções estatais planejadas, sobretudo na Região Metropolitana de Salvador (RMS), através da oferta de terrenos dotados de infraestrutura e incentivos fiscais, entre outras ações. Segundo Pessoti (2008), esta política foi responsável por uma média de crescimento anual de 7\% do Produto Interno Bruto (PIB) do Estado, entre as décadas de 60 e 70, ancorada, principalmente, pelo Centro Industrial de Aratu e o Complexo Petroquímico de Camaçari.

Para Pessoti e Pessoti (2010), os anos de 70 podem ser entendidos como a década que consolida de vez o processo de industrialização iniciado nos anos 50, sobretudo após a implantação do Complexo Petroquímico de Camaçari (COPEC) quando o ambiente industrial baiano passa a dar mais atenção ao setor secundário, colocando-o em condições mais favoráveis.

De acordo com Guerra e Teixeira (2000), a industrialização baiana foi direcionada aos setores químicos devidos a três motivos:

i) O Estado era, na época, o maior produtor de petróleo do país e até então já possuía uma refinaria (Landulfo Alves). Tinha-se, assim, uma base técnica para a implantação do polo petroquímico.

ii) Nos primeiros anos da década de 70, havia carência na produção nacional de alguns insumos básicos usados pela indústria de transformação do Centro Sul. 
iii) O Governo Federal tinha entre seus objetivos, a diminuição dos desequilíbrios regionais. Dado este contexto, diversos empreendimentos foram implantados, destacando-se os realizados no COPEC. Com o passar do tempo, sua consolidação fez com que a participação relativa do setor primário no PIB Setorial Baiano diminuísse de 40 \%, em 1960, para 16,4\% em 1980. O setor secundário, por sua vez, no mesmo período, quase triplica sua participação, saltando de 12 \% para $31,6 \%$, colocando a economia baiana numa nova posição.

Neste contexto, Carvalho Junior et al. (2002) observam que, no início da década de 70, influenciado pelos ideais da Superintendência do Desenvolvimento do Nordeste(SUDENE), há uma tentativa, por parte do governo do Estado, de especializar e interiorizar o desenvolvimento industrial da Bahia por meio de metas que visavam estabelecer mudanças na estrutura produtiva, tendo como principal objetivo dinamizar os municípios do interior da Bahia, integrando-os à matriz produtiva do Estado. Em busca de concretizar este objetivo, foram implementados, em sua concepção original, distritos industriais nos municípios de Ilhéus, Jequié, Vitória da Conquista e Juazeiro, cujas áreas eram admitidas como estratégicas, pelo Governo do Estado, seguindo a lógica estratégica de "descentralização concentrada", pautada em empreendimentos industriais em locais escolhidos em função da possibilidade de efeitos de transbordamento para os municípios situados na circunvizinhança dos Distritos industriais (SOUTO et al.,2017).

Consolida-se em razão disto, na Bahia, na década de 70, a estrutura industrial de perfil complementar às indústrias do Centro-Sul, centrada basicamente na produção de bens intermediários, principalmente da indústria petroquímica. À esta concentração setorial une-se a concentração espacial, caracterizando fortemente o novo perfil econômico do Estado. Em decorrência das externalidades ${ }^{4}$ e das economias de aglomeração ${ }^{5}$ geradas pelas indústrias e infraestrutura já instaladas na RMS, fatores como logística, serviços de apoio e manutenção e a proximidade com fornecedores aumentam o poder de atração desta mesma região, em especial para as indústrias dinâmicas, mais modernas e tecnologicamente mais sofisticadas. Nesse universo temos as dos ramos dos produtos químicos, plásticos, farmacêuticos e veterinários (MASCARENHAS, 2001).

Em suma, todo o conjunto de empreendimentos iniciados pela construção da Refinaria Landulfo Alves, nos anos 50, até a implantação do Polo Petroquímico de Camaçari, nos anos 70, serviram para a consolidação da industrialização baiana, alterando de forma significativa e definitiva a estrutura econômica, social e política do Estado ao mudar de uma vez por todas o peso do PIB estadual com redução significativa da agricultura e com crescimento constante da participação do setor secundário, com destaque para os setores

\footnotetext{
${ }^{3}$ Processo de maior democratização do espaço industrial do país, mas que acabou por se concentrar apenas em cidades específicas.

4 Conceito econômico referente à quando alguma empresa ou indústria executa uma ação que gera efeitos positivos ou negativos que vão além de seu cliente ou consumidor final, ou seja, a pessoas terceiras a sociedade.

${ }^{5}$ Etapa de um processo de industrialização onde empresas se concentram em uma determinada região do espaço geográfico.
} 
químico, petroquímico, metalúrgico, siderúrgico e extrativa mineral, cravando de vez a posição da Bahia como uma das principais fornecedoras nacionais de bens intermediários (NÓVOA, 1979).

Para Almeida (2009), em 1970, Feira de Santana, através da elaboração do Plano Diretor do Centro Industrial do Subaé (PDCIS), começa a estabelecer a criação do Distrito Industrial do Subaé com o objetivo de estimular a expansão deste município como polo secundário e auxiliar da Bahia de modo a funcionar como complemento do eixo industrial que já havia se estabelecido na capital. Características marcantes como sua privilegiada localização rodoviária, a já existência de um pequeno parque industrial, a instalação do Centro de Desenvolvimento Industrial (CEDIN) e os incentivos fiscais para as indústrias de bens de consumo final foram decisivas na tentativa de promoção de um crescimento econômico local por parte do Distrito Industrial do Subaé. A instalação deste distrito industrial em Feira de Santana, promoveu uma mudança na configuração socioeconômica e populacional da cidade, dando a ela características mais urbanas (maior infraestrutura urbana e concentração populacional na cidade).

Segundo Cruz (1999), o crescimento da indústria local na década de 70, e parte dos anos 80, vem acompanhado da expansão de atividades terciárias com fortes ligações aos movimentos de valorização de terras rurais, industriais e urbanas. A construção civil e a urbanização comercial, advindas dos investimentos governamentais que facilitavam o acesso às cidades do interior, trouxeram novas mudanças no cenário urbano e no cenário econômico para o município de Feira de Santana como a construção de um anel rodoviário e o surgimento de novos conjuntos habitacionais populares que atendiam tanto aos interesses especulativos do capital imobiliário quanto aos interesses comerciais e industriais em escoar e regionalizar os processos produtivos, tendo novamente o Estado um papel importante na transformação econômica social de Feira de Santana.

Desta forma, o surgimento do CIS, enquanto motor de novos processos produtivos - seja com as economias de escala de novos produtos, seja quanto na atração de novas empresas de variados setores -, acaba por incitar, segundo Góes Filho (2001), novas formas de cooperação para os processos produtivos, novos arranjos locais com as indústrias instaladas, novos arranjos sociais (em termos econômicos, com o crescimento da classe industriaria na cidade), e novas alianças políticas entre o governo municipal e o estadual com a classe industrial, ampliando, de forma significativa, o poder de articulação da região de Feira de Santana e, por conseguinte, a capacidade de partilha dos investimentos públicos.

Essa dinâmica não ficou limitada apenas ao crescimento urbano, o espaço rural municipal também alterou suas configurações da estrutura fundiária, das relações de trabalho e ampliou as relações campocidade, com novas ruralidades relacionadas ao modelo urbano/econômico que a cidade e o município impuseram como padrão de desenvolvimento econômico (ARAÚJO, 2015).Nesta esteira, de alguma, forma o estigma de roça e ruralidade enquanto espaço inferior de vida, especialmente, no nordeste do país e em Feira de Santana, aprofunda-se cada vez mais e distancia a dimensão rural de um desenvolvimento profícuo e necessário. 
Estabelecidos estes condicionantes, este artigo pretende analisar dentro da perspectiva da relação campo-cidade, os impactos deste novo modelo industrial e urbano nesta relação no município de Feira de Santana, observando o comportamento de algumas variáveis como a organização populacional, a organização urbana, a estrutura fundiária do município entre outros.

Metodologicamente, para dar conta dessa pesquisa na perspectiva supramencionada, lançaremos mãos primeiramente de uma revisão teórica sobre o processo de industrialização tanto do estado da Bahia quanto do município de Feira de Santana, de modo a ressaltar o desenvolvimento de sua formação econômica desde o início da fixação populacional no século XVIII através da criação da feira de gado até a instalação do Centro Industrial do Subaé na década de 1970 do século XX. O objetivo dessa análise teórica/histórica é de fornecer elementos qualitativos (explora informações mais subjetivas e em profundidade) para a análise quantitativa (aquela que se dá na coleta de dados estatísticos para testar uma hipótese).

O banco de dados utilizado para a elaboração deste trabalho corresponde as informações encontradas nos Censos Populacionais do IBGE (Instituto Brasileiro de Geografia e Estatística) que embasarão as análises feitas pela hipótese deste trabalho: de que o processo de industrialização baiano e feirense, de modo especifico a instalação do Centro Industrial do Subaé na década de 1970 contribuiu para a mudança de dinâmica populacional de Feira de Santana do agrário para o urbano.

\section{BREVE CARACTERIZAÇÃO DO MUNICÍPIO DE FEIRA DE SANTANA}

Nos primórdios do século XVIII, em uma região localizada entre o litoral úmido e o interior do semiárido do estado da Bahia, através de uma fazenda denominada "Sant'Ana dos Olhos d'Água, de propriedade do casal Domingos Barbosa de Araújo e Ana Brandôa, dá-se início a fixação humana que iria resultar na criação da cidade de Feira de Santana. Segundo Santo (2003), após a criação de uma capela dedicada a Santa Ana e a São Domingos, a mesma logo se tornou um ponto de parada de descanso e hidratação para toda a espécie de viajantes, sobretudo os boiadeiros e tropeiros, em viagem de ida ou vinda para o sertão.

Em virtude desse fluxo populacional, em um curto espaço de tempo, algumas pessoas começaram a se fixar ao redor da região da fazenda, de modo que um pequeno comércio foi estabelecido entre estas e os vaqueiros que por ali passavam, surgindo assim uma feira de gado e de comércio de pequenos produtos essenciais para a subsistência dos moradores e dos viajantes.

Segundo Pedreira (1983, p.15)," por volta de 1825 já existia no referido local, o Arraial de Sant'Ana dos Olhos D'Água, onde as terças-feiras de cada semana se ajuntam de 3 a 4 mil pessoas, e onde havia uma grande feira de gado." Esta feira era justificada em virtude da localização privilegiada do Arraial entre o Recôncavo e o Médio São Francisco, e das condições naturais ali encontradas (abundância de pastagens naturais e de água). 
Assim, observa-se que bastou apenas um século para que Feira de Santana passasse de simples aldeia (pequeno povoado rural) para a localidade com a mais importante Feira da Bahia. Essa feira era a base de sua economia e tornou-se ao longo do tempo um espaço ou um ambiente consubstanciado para além dos negócios, um verdadeiro espaço de encontro entre ciências, saberes e sabores, conforme discute Lima (2017).

A agricultura existia em função da demanda dos comerciantes e da subsistência dos moradores, sendo caracterizada pela grande produção de alimentos. Só mais tarde apareceu timidamente a plantação de fumo e de algodão. Vale ressaltar que tanto os fardos de fumo e de algodão eram envoltos em couro, o que caracterizava a abundância da economia pecuarista local (SANTO 2003).

A inserção da vila nos processos de articulação, desconcentração e interiorização produtiva começam após 1860, com a percepção por parte do governo da Província da Bahia do aumento dos fluxos comerciais e do crescimento da feira de gado, que as estradas que interligavam o interior do estado a capital Salvador encontravam-se em estado precário, fazendo com que o escoamento da produção ocorresse em vários dias de viagens em transportes ainda mais rudimentares como carros de bois e no lombo de animais. Nesta perspectiva, já em 1917, no governo de Antônio Sodré Aragão é traçado o primeiro plano de construção de estradas tendo o trecho Salvador-Feira de Santana (que já havia sido elevada a categoria de cidade em 1873), como o principal foco, sendo já em 1938, segundo Cruz (1999, p.177), o “município já experimentava o fortalecimento de sua posição como foco de irradiação e convergência de um sistema de rodovias, com recursos públicos da Bahia e da União".

O município seria beneficiário, assim, da confluência de interesses que reforçavam sua posição estratégica, perante os fluxos de capitais com destino ao Nordeste e a Salvador, fortalecendo o comércio local e gerando investimentos em atividades diversificadas. Desde cedo, os excedentes obtidos com a atividade comercial haviam proporcionado o surgimento de uma incipiente indústria beneficiadora do fumo e do preparo de carnes, couros e peles, cujo valor da produção era sobrepujado pela pecuária ou mesmo pela agricultura.

Desde 1860, aliás, registrava-se a presença de unidades de pequeno porte, baseadas em trabalhos manuais, com pouca utilização de vapor ou de máquinas. Em 1940, Feira de Santana já possuía 29 estabelecimentos, entre usinas de beneficiamento e fábricas de pequeno porte (CRUZ, 1999).

A migração do campo para a cidade com a sobreposição da atividade industrial/mercantil sobre a agrária segundo Brito (2007) se dá a partir do momento em que os migrantes entendem que é nas grandes cidade industriais/mercantis que se encontram as melhores oportunidades para uma ascensão social e uma melhoria no padrão de vida.

Já para Cardi e Peri (2016):

[...] ]os imigrantes e nativos podem ser classificados em um número relativamente pequeno de grupos de habilidades e em seguida modelam a imigração como uma alteração na oferta de diferentes tipos de trabalho (CARDI E PERRI, 2016, p.1336). 
Estabelecidas estes condicionantes, a figura 1 demonstra a evolução territorial do município de Feira de Santana e região de 1827 até 1970.

\section{Imagem 1: Evolução territorial do Município de Feira de Santana e região (1827-1970)}
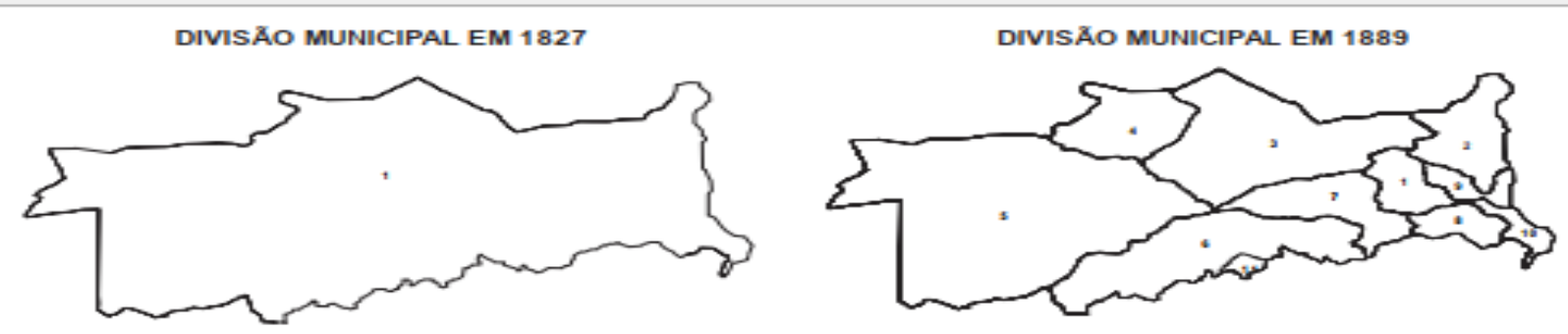

DIVISÅO MUNICIPAL EM 1940

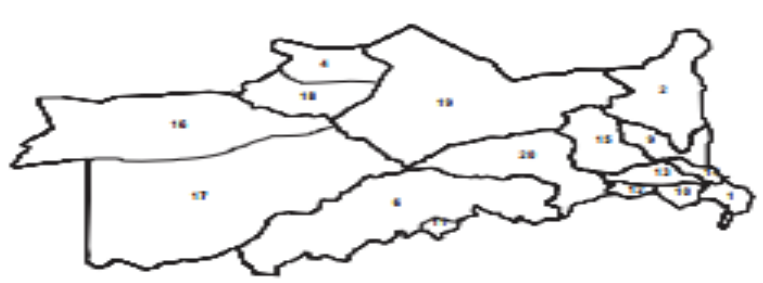

DIVISÅO MUNICIPAL EM 1970

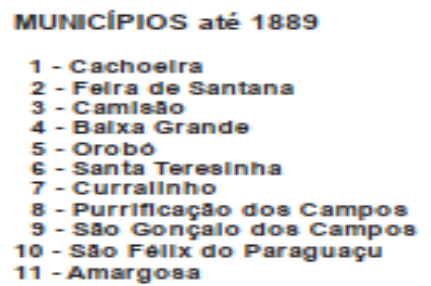

Fonte: Araújo (2015)
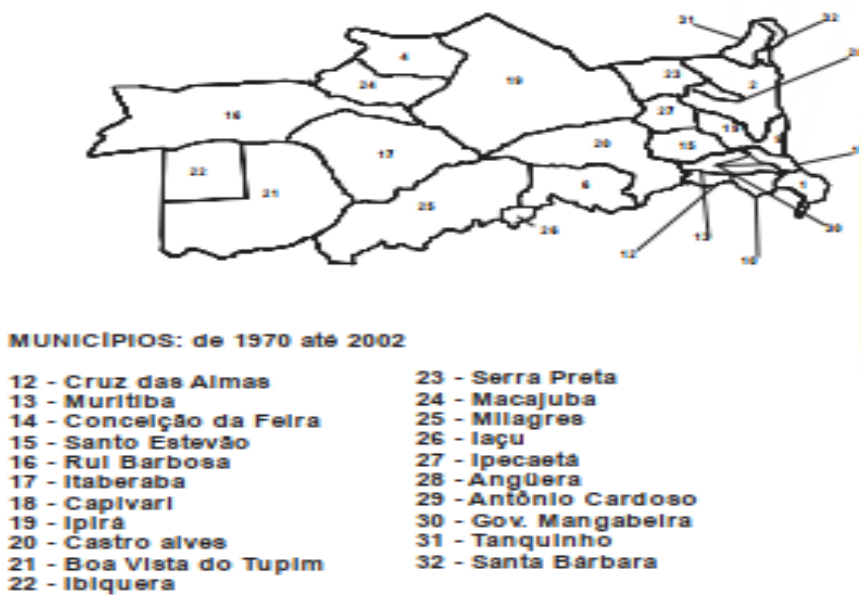

Esta "indústria nascente" feirense dos anos 1940 enfrenta dois problemas limitantes ao seu desenvolvimento no município como principal atividade produtiva: o primeiro diz respeito ao próprio tamanho do mercado consumidor local e regional, ainda marcado por baixos níveis de renda; e em segundo e mais importante, a concorrência maciça de produtos mais industrializados advindos de Salvador. Estabelecida esta conjuntura, a indústria local feirense num primeiro momento foca sua produção para o mercado local e regional em produtos agrícolas de baixo valor agregado já de forte presença local (fumo, algodão e peles)e produtos complementares a produção das cidades vizinhas. Esse foco é mantido na década seguinte e graças ao mercado local, Feira de Santana experimenta um grande crescimento industrial durante a década de 1940 e 1950.

A partir dos anos 1960, com o crescimento urbano e industrial de Salvador através dos processos de industrialização já explicitados na introdução deste trabalho, onde segundo Freitas (1996) e Cruz (1999), a capital do estado integra-se produtivamente a lógica do capital industrial nacional, Feira de Santana começa 
de fato a mudar sua estrutura e sua relação campo-cidade, quando passa a atuar como um centro de serviços de apoio a transportes e passageiros, reforçando ainda mais o seu papel histórico de entroncamento comercial, fazendo parte agora também da cadeia produtiva deste capital mercantil e industrial. Observa-se em que pese a pressão industrial pela urbanização como algo superior no processo econômico uma relação ainda dialógica entre as dimensões campo-cidade neste município.

Com o advento das mudanças, e a consequente implantação do CIS, a atividade industrial de Feira de Santana se concentra e se organiza, uma vez que antes eram dispersas e desorganizadas, espalhadas pela malha urbana do município sem qualquer tipo de conexão entre elas. No que diz respeito à estrutura fundiária, Araújo (2015, p.19) destaca que:

"O município possui, como a maioria dos demais municípios baianos, uma estrutura fundiária concentrada, prevalecendo pequenas propriedades rurais, numa mini fundiarização promovida, em especial pela dinâmica municipal de sua relação campo cidade, pois o município possui uma política de crescimento e desenvolvimento urbano, a qual o espaço rural não está contemplado. A mini fundiarização garante a manutenção constante da oferta de terras para lotes urbanos".

Uma característica observada por Araújo (2015) e Freitas (2014) é que estas pequenas propriedades rurais de Feira de Santana obedecem à mesma lógica de outros municípios baianos: proprietários com um grande número de herdeiros, o que "força" aqueles que não herdarão a terra ou a trabalharem muito cedo ajudando seus pais ou na maioria dos casos, a buscar sustento e moradia nas cidades próximas, fazendo, com efeito, uma articulação forçada ou "naturalizada" entre as dimensões urbanas e rurais sem perceber a imposição do processo econômico industrial.

Neste contexto inicia-se assim as relações de trabalho que vão desde o meeiro até o arrendamento de terras, passando pelo trabalho em atividades não agrícolas e no emprego ou subemprego quase sempre na cidade ou no povoado mais próximo de sua propriedade (trabalho acessório), distribuindo-se da seguinte forma: conforme o sexo, a idade e a escolaridade; primeiro dos jovens, não deixando também, de acontecer com os pais - para as meninas, as mais diversas atividades domésticas na casa de terceiros, e no comércio local; para os meninos atividades de auxiliar das mais diversas profissões, principalmente na construção civil e nas oficinas de automóveis em ambas as situações, o peso da falta de escolaridade e qualificação profissional são os maiores entraves (ARAÚJO, 2015).

A fragmentação dos lotes faz parte da estratégia do processo de (re) produção da pequena propriedade rural. Um dos fatores que contribui para este processo é a realização do matrimônio muito precoce dos filhos, que passam a trabalhar e residir, construindo mais uma casa na mesma terra dos pais. As filhas por sua vez, herdarão as terras que seus cônjuges herdarem - caso estes possuam, e que neste primeiro instante, por motivo da união, não abandonam a terra - ela servirá tanto para moradia como para sustento ou complementação de renda para a nova família (FREITAS, 2014). 
Com o decorrer do tempo observa-se que o processo de fragmentação das pequenas propriedades rurais, vem acelerando e se mantendo, principalmente, com a disponibilidade de novos elementos que antes não faziam parte do cotidiano destas famílias de pequenos produtores, como a energia elétrica e água encanada, sistema de telefonia e internet, o posto médico, pequenos comércios diversos, serviços de estética e beleza e em alguns casos a coleta de lixo, a escola primária e de ensino médio, o transporte coletivo - dos mais diversos e a todo instante, e mais ainda a revolução urbana da motocicleta(ARAÚJO,2015).

Estes novos processos dentro do espaço rural, aliado ao crescimento das cidades e o nascimento do distrito industrial do Subaé, colabora para que as relações campo-cidade no município de Feira de Santana se intensifiquem através de uma relação "simbiótica" entre ambos os espaços. A cidade (e por consequência a indústria) perpassa a contratação de mão-de-obra do campo; famílias camponesas passam a morar em sua totalidade (ou em parte) na cidade, seja através da venda de terras para angariar fundos para o sustento familiar, seja para transformar o espaço rural em uma "segunda residência" dos fins de semana.

Porém, nem todos conseguem se enquadrar nestas questões levantadas no parágrafo anterior, o que leva aos moradores oriundos do espaço rural a se instalarem em zonas periféricas da cidade (com terrenos ou alugueis mais baratos), uma vez que, a fonte de renda destes indivíduos é o subemprego ou o mercado informal, pois como destaca Freitas (2014, p.23), "o Estado nunca se preocupou em amparar os que consideram subcidadãos, gerando no mínimo a condição de subordinação tanto rural quanto urbana".

Desta forma, na próxima seção deste artigo, pretende-se analisar a relação atual campo-cidade na cidade de Feira de Santana através da base de dados demográficos do município, os conjuntos habitacionais e residenciais, a urbanização e as complexidades do meio urbano-rural.

\section{AS RELAÇÕES CAMPO-CIDADE EM FEIRA DE SANTANA}

A proposta desta última seção do artigo é de esmiuçar a relação campo-cidade na cidade de Feira de Santana através de uma análise dos dados do Censo de 2010, cujo objetivo faz-se necessário para entender as bases desta relação e o contexto do qual surgem novos condicionantes desta relação no referido município.

A relação campo-cidade deve ser entendida a partir da ausência de delimitações rígidas ou barreiras fixas, entre os espaços rural e urbano, pois ambos são constituídos de elementos presentes, tanto em um, como no outro. Todavia, o conjunto de forças que atuam em ambos, de modo particular os processos de urbanização e industrialização, delineiam novas fronteiras ou formas de relações sociais, econômicas, produtivas e políticas, as quais possuem rebatimentos na organização do espaço.

Hoje, na relação campo-cidade, o urbano tem se mostrado o elemento dominante subordinando o campo à cidade, situação que emerge como uma característica recente, a partir do advento da industrialização, fenômeno que em escala mundial se intensifica no Brasil nos decênios de 1960 e 1970. Porém, a "modernização" não ficou restrita a cidade e a indústria, uma vez que ao traçar o quadro de 
mudanças econômicas de nossa história recente, observamos que o campo não ficou banido do contexto de mudanças produtivas. O espaço rural, subordinado ao capital e aos interesses urbanos, tem sua produção orientada para atender as necessidades diretas e indiretas da cidade (ARAÚJO, 2015).

Uma primeira análise da relação campo-cidade em Feira de Santana se dá na demografia do município. Ao analisarmos os dados disponíveis no Censo Demográfico do IBGE (Instituto Brasileiro de Geografia e Estatística), percebe-se que há um aumento considerável da população do município após 1950(início do processo de industrialização baiana).

Tabela 1: Crescimento demográfico de Feira de Santana (1872 - 2010)

\begin{tabular}{|c|c|c|}
\hline Período/Ano Base & $\begin{array}{c}\text { População Total de Feira de } \\
\text { Santana }\end{array}$ & $\begin{array}{c}\text { Taxa de Crescimento } \\
\text { Populacional (em \%) }\end{array}$ \\
\hline 1872 & 32.955 & - \\
\hline 1890 & 38.621 & 17,91 \\
\hline 1900 & 61.758 & 59,60 \\
\hline 1920 & 77.600 & 25,65 \\
\hline 1940 & 83.268 & 7,30 \\
\hline 1950 & 107.205 & 28,74 \\
\hline 1960 & 141.757 & 32,22 \\
\hline 1970 & 190.076 & 34,08 \\
\hline 1980 & 291.504 & 53,36 \\
\hline 2000 & 406.447 & 39,43 \\
\hline 2010 & 481.137 & 18,37 \\
\hline
\end{tabular}

Fonte: IBGE (2010)

É importante destacar algumas questões a respeito da dinâmica demográfica do referido município, sobretudo entre as décadas de 50 e 60, que apesar da emancipação política de municípios ao redor de Feira de Santana (Tanquinho, Irará, Santa Bárbara entre outros), não alteraram o pujante crescimento populacional do município de Feira de Santana, no sentido da ocupação das populações desses municípios nas suas respectivas localidades, certamente, mais rurais.

Ao analisarmos a composição da população do município de Feira de Santana (aqui embasada pelos locais de residência) nos referidos anos, também é possível notar a mudança de perfil da população do rural para o urbano, conforme poderemos observar na tabela 2 abaixo.

Conforme os dados dos Censos do IBGE supramencionados, entre 1940 e 2010 há uma mudança no perfil da população feirense. Até os anos 1960, a população do município era composta majoritariamente pela parcela correspondente da população rural. Após os anos 1970(com a instalação do CIS e os processos de integração produtiva por parte do governo nacional e estadual), a população urbana passa a responder de forma majoritária na composição populacional. 
Tabela 2: Composição da população do Município de Feira de Santana, quanto a ocupação dos espaços

\begin{tabular}{|c|c|c|}
\hline ANOS & Total População Urbana & Total População Rural \\
\hline 1940 & 19.600 & 63.608 \\
\hline 1950 & 34.277 & 72.928 \\
\hline 1960 & 69.884 & 71.873 \\
\hline 1970 & 134.263 & 55.813 \\
\hline 1980 & 233.905 & 57.599 \\
\hline 1991 & 348.973 & 56.875 \\
\hline 2000 & 431.530 & 46.607 \\
\hline 2010 & 510.635 & 46.007 \\
\hline
\end{tabular}

A dinâmica da migração populacional é melhor observada ao analisarmos em termos percentuais a participação urbana e rural em Feira de Santana em termos populacionais durante o período 1940-2010. Os dados são apresentados na tabela 3.

Tabela 3: Composição da população de Feira de Santana (\%)

\begin{tabular}{|c|c|c|c|}
\hline Anos & População Total & População Urbana (\%) & População Rural (\%) \\
\hline 1940 & 83.268 & 23,62 & 76,38 \\
\hline 1950 & 107.205 & 31,97 & 68,03 \\
\hline 1960 & 141.757 & 49,29 & 50,71 \\
\hline 1970 & 190.076 & 70,63 & 29,37 \\
\hline 1980 & 291.504 & 80,24 & 19,76 \\
\hline 1991 & 406.447 & 85,86 & 14,14 \\
\hline 2000 & 481.137 & 89,68 & 10,32 \\
\hline 2010 & 556.462 & 91,76 & 8,24 \\
\hline
\end{tabular}

Fonte: IBGE (2010)

Com base nos dados da tabela 3, percebe-se que até 1950, a população do município de Feira de Santana era majoritariamente rural (68,03\%). Os estudos de Araújo (2015), Guerra e Teixeira (2002) e Cavalcantti(2008), afirmam que a partir de 1950, tanto no estado como no país são observados o início de processos intensos de crescimento (dirigido por agentes econômicos, com destaque para o papel do Estado, através de ofertas de terrenos dotados de infraestrutura e incentivos fiscais e do capital financeiro internacional), de urbanização e modernização das atividades produtivas (principalmente a indústria), que resultou em um crescimento econômico mais acelerado.

No caso especifico de Feira de Santana, os dados disponibilizados pelo IBGE corroboram com as teses de Carvalho Júnior et al (2002) Cruz (1999) e Almeida (2009), de que a partir da década de 70 do século passado, com a tentativa por parte do governo baiano de dinamizar a produção do estado via industrialização das cidades do interior, aliado ao caso específico do município, com a implantação e 
instalação do CIS (Centro Industrial do Subaé), há uma intensa migração populacional do campo para a cidade em busca de mais e melhores oportunidades de trabalho, provocando assim mudanças de ordem social, econômica e urbana, como destaca Araújo(2015), com o surgimento dos assentamentos subnormais (favelas); a criação de novos conjuntos habitacionais para acolher os novos trabalhadores, expandindo a malha urbana do município cada vez mais em direção ao externo de seu anel viário (ARAÚJO,2015); o inchaço do setor terciário da economia que passa a abrigar com remunerações baixíssimas aqueles que não conseguem emprego no CIS (SEI,2000).

Neste contexto, observamos também a apreciação ou forte tendência de valorização dos elementos que formam as relações urbanas, em detrimento dos elementos que podem fortalecer as relações do campo como educação do campo, cultura rural, serviços diversos entre outros elementos de valorização política dos atores sociais rurais.

\section{CONSIDERAÇÕES FINAIS}

A relação campo-cidade em um primeiro momento nos parece como dois mundos distintos não correlacionados entre si. Porém, ao entendermos que as funções do campo e da cidade não são meramente administrativas e sim, lugar de relações produtivas e sociais, é possível estabelecer relações e correlações entre os dois espaços como modo de tentar compreender os efeitos que um exerce no outro, ou seja, uma relação dialética integrativa.

Dentro desta perspectiva, o presente artigo teve como principal objetivo analisar como o processo de industrialização baiano, iniciado formalmente na década de 50 no século passado influenciou no processo de industrialização e urbanização da cidade de Feira de Santana, que tem como marco a implementação e instalação do CIS (Centro Industrial do Subaé) nos anos 70. Nesta perceptiva, inferimos através da análise dos dados do Instituto Brasileiro de Geografia e Estatística que a partir dos anos 50 há uma transformação na composição da população do município de Feira de Santana, antes hegemonicamente rural, para a hegemonia urbana, acompanhando o processo de urbanização e industrialização brasileiro.

Com efeito, dentre as causas desta nova hegemonia urbana, podemos destacar os processos de modernização produtiva, a expansão da malha urbana do município principalmente fora do anel viário, com a criação de novos conjuntos habitacionais (criação e ampliação do mercado imobiliário no contexto industrial), bem como o surgimento de favelas para agrupar esta nova conjuntura demográfica da cidade, que vinha sobretudo para servir como mão de obra, seja para o distrito industrial que ora surgia, seja para a ampliação do setor terciário que acolhia aqueles que não conseguiam emprego no setor industrial.

\section{REFERÊNCIAS BIBLIOGRÁFICAS}

ALMEIDA, Janeide Oliveira da Silva. A implantação do Centro Industrial do Subaé em Feira de SantanaBahia através de uma industrialização planejada. In: ENCONTRO DE GEÓGRAFOS DA AMÉRICA LATINA, 12, 2009, Montevidéu. Anais. Montevidéu: EasyPlanners, 2009. 
ARAÚJO, Wodis Kleber Oliveira. A relação campo-cidade no município de Feira de SantanaBA:Renda da terra, campesinato e ruralidades. Tese (Doutorado em Geografia)-Pós Graduação em Geografia, Universidade Federal de Sergipe, São Cristovão, 2015.

BRITO, Fausto. As migrações internas no Brasil: um ensaio sobre os desafios teóricos recentes. [S.l: s.n.], 2007. Disponível em: Acesso em: 21 ago. 2019.

CARD, David; PERI, Giovanni. Immigration Economics by George J. Borjas: A Review Essay. Journal of Economic Literature, v. 54, n. 4, p. 1333-1349, dez. 2016.

CAVALCANTI, Luiz Ricardo. Maturidade Tecnológica e Intensidade em Pesquisa e Desenvolvimento: o caso da indústria petroquímica no Brasil. Revista Organizações \& Sociedade, Salvador, vol.5, p.121-143, 2008.

CARVALHO JÚNIOR, César Vaz de ;PESSOTI, Gustavo Casseb, PEREIRA,Ítalo Guamais Aguiar. Panorama da Economia Baiana sob a ótica do PIB 1975/2000-Dez Anos de Economia Baiana. Revista Bahia Análise \& Dados, Salvador, v.16, p.413-430, 2002.

CRUZ, Rossine Cerqueira Da. A inserção de Feira de Santana (BA) nos processos de integração produtiva e de desconcentração econômica nacional. Tese (Doutorado em Economia). Instituto de Economia, Universidade de Campinas. 1999.

FREITAS, Nacelice Barbosa.Urbanização em Feira de Santana: Influência da Industrialização - 19701996. Dissertação (Mestrado em Arquitetura e Urbanismo)- Faculdade de Arquitetura, Universidade Federal da Bahia, Salvador, 1996.

FREITAS, Nacelice Barbosa. O descoroamento da princesa do sertão : De "chão" a território, o "vazio" no processo da valorização do espaço. Tese (Doutorado em Geografia)-Pós Graduação em Geografia, Universidade Federal de Sergipe, São Cristovão,2014.

GUERRA, Oswaldo; TEIXEIRA, Francisco. Estratégias para o desenvolvimento da indústria na Região Metropolitana de Salvador. Revista Bahia Século XXI, Salvador, v.01, p. 147-204, 2000.

GUERRA, Oswaldo; TEIXEIRA, Francisco. 50 Anos da Industrialização Baiana: do enigma a uma dinâmica exógena e espasmódica. Revista Bahia: Análise\&Dados,Salvador, v.10, p. 87-98, 2002.

IBGE. Censo Demográfico e Agricultura Familiar. Bahia. Rio de Janeiro: IBGE, 1950, 1960, 1970, 1980, 1991, 2010.

LIMA, José Raimundo de Oliveira. Economia Popular e Solidária e Desenvolvimento Local: uma relação estratégica. Feira de Santana-BA, Novas Edições Acadêmicas, 2017.

MASCARENHAS, Albérico Machado. A atividade de fomento na Bahia: uma retrospectiva dos últimos 50 anos. Reflexões de economistas baianos, Salvador, vol.01. p. 62-77, 2001.

NÓVOA, Jorge Luiz Bezerra. Raizes da dependência econômica da Bahia. Dissertação (Mestrado em Economia)-Faculdade de Economia, Universidade Federal da Bahia, Salvador, 1979.

PEDREIRA, Pedro Torres. Município de Feira de Santana: das origens ás instalações. $1^{\circ}$ ed,Salvador:Gráfica e Editora LTDA. 1983.

PESSOTI, Gustavo Casseb. Um Estudo da Política Industrial na Bahia entre 1950 e 2005. Dissertação (Mestrado em Desenvolvimento Regional e Urbano)-PPDRU, Unifacs, Salvador, 2008. 
PESSOTI, Bruno Casseb; PESSOTI, Gustavo Casseb. A economia baiana e o desenvolvimento industrial: Uma análise do período 1978-2010. RDE- Revista de Desenvolvimento Econômico, Salvador, v.22, p.22$45,2010$.

SANTO, Sandra Medeiros. O desenvolvimento urbano em Feira de Santana. Revista Sittientibus,Feira de Santana n.28,p.9-20, 2003.

SEI. Superintendência de Estudos Econômicos e Sociais da Bahia. Evolução territorial e administrativa do Estado da Bahia: um breve histórico. Salvador, 2000.

SOUTO, Roberto Lucas Spínola; PESSOTI, Fernanda Calasans Costa Lacerda; PESSOTI, Gustavo Casseb; SPINOLA, Noelio Dantaslé. Do Plano a realidade: Uma análise do Programa de Implantação dos distritos industriais no interior do estado da Bahia. In: ENCONTRO DE ECONOMIA BAIANA, 13,2017, Salvador. Anais. Salvador. SEI, 2017. 